\title{
RELEASE OF THE NEW SOUTH WALES MOTHERS AND BABIES REPORT 2002
}

\section{Frank Beard}

NSW Public Health Officer Training Program NSW Department of Health

\section{Lee Taylor}

Centre for Epidemiology and Research NSW Department of Health

The report New South Wales Mothers and Babies 2002, the NSW Department of Health's latest report on the health of mothers and babies in NSW, was released in January 2004.

The report shows a continued trend towards later childbirth, with the number of mothers aged 35 years and over increasing from 13,839 (16.3 per cent) in 1998 to 15,872 (18.8 per cent of all mothers) in 2002, and the number of mothers less than 20 years of age falling from 4,118 (4.8 per cent) in 1998 to 3,652 (4.3 per cent) in 2002. Caesarean section rates continue to increase, rising from 19.0 per cent in 1998 to 24.9 per cent in 2002. Over the same period, the rate of normal vaginal birth has fallen from 69.5 per cent to 64.2 per cent. Delivery by Caesarean section continues to be more common among privatelyinsured mothers than publicly-insured mothers, rising from
24.4 per cent to 30.0 per cent among privately-insured mothers and from 15.4 to 19.4 per cent among publiclyinsured mothers between 1997 and 2001.

The total number of births in NSW has remained stable over the last five years, with 86,005 babies born to 84,587 mothers in 2002. Around one in four mothers were born overseas in 2002 with the most common countries of birth, other than Australia, being the United Kingdom (2.8 per cent), New Zealand (2.4 per cent), China (2.2 per cent), Vietnam (2.1 per cent), and Lebanon (2.0 per cent).

In 2002, the overall perinatal mortality rate (stillbirth or livebirth with subsequent death within 28 days) of 8.7 per 1,000 births was the lowest reported in the past 10 years. While the perinatal mortality rate in babies born to Aboriginal or Torres Strait Islander mothers was higher, at 11.0 per 1,000 births, this was also the lowest rate reported over the past 10 years. Since 1998 the overall rate of low birthweight (less than 2,500 grams) has remained stable at around six per cent, and the percentage of babies born prematurely (less than 37 weeks gestation) has remained stable at about seven per cent. Over the same period, the rates of low birthweight and prematurity in babies born to

\section{FIGURE 1}

PERINATAL DEATHS BY OBSTETRIC CAUSE AND YEAR, NSW, 2001-2002

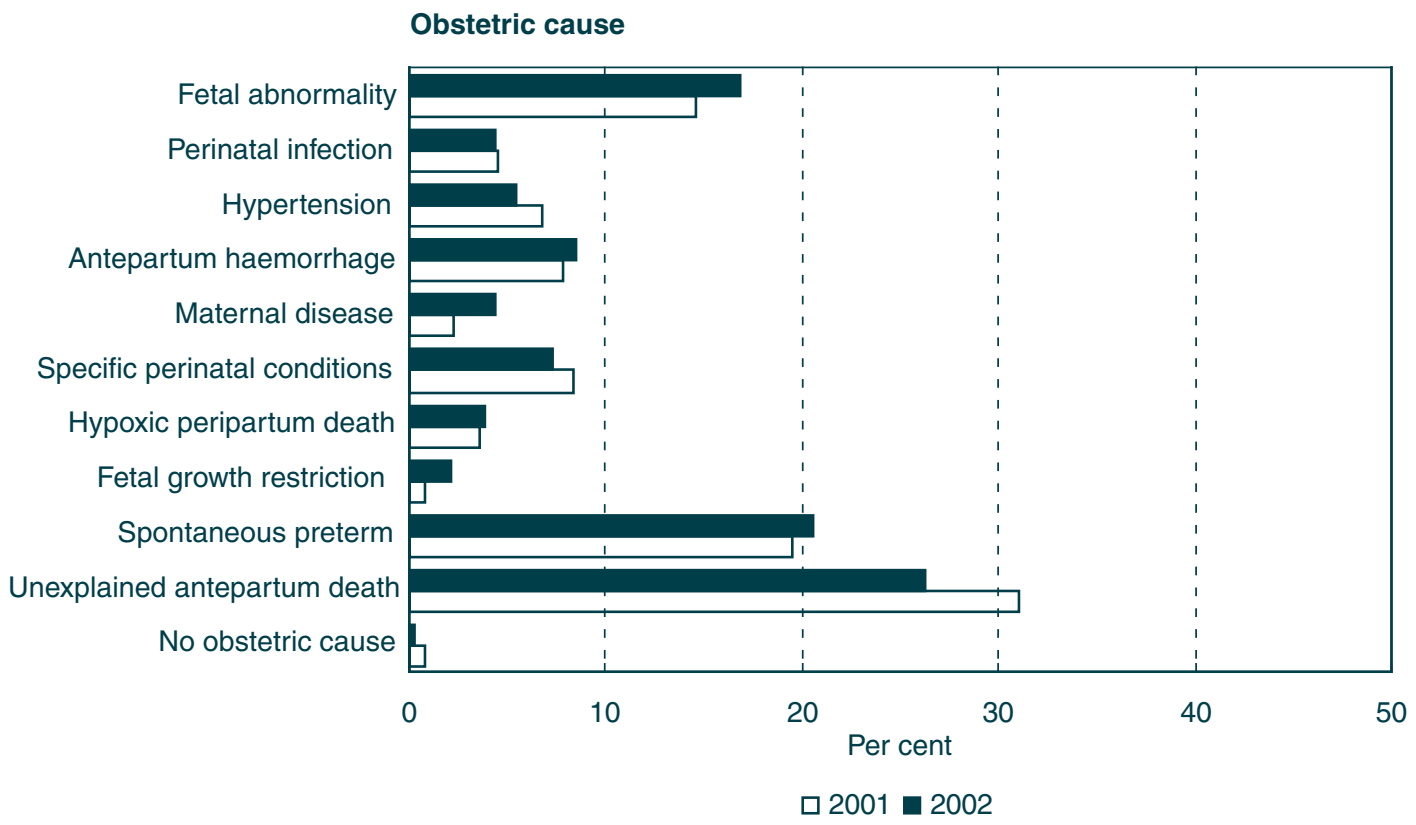

Source: NSW Maternal and Perinatal Committee, NSW Department of Health. 


\begin{tabular}{|c|c|c|c|c|c|}
\hline ờ & 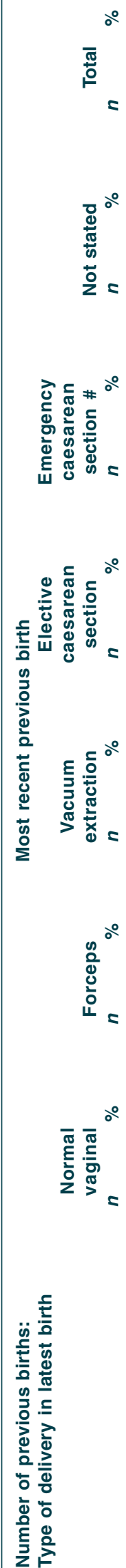 & 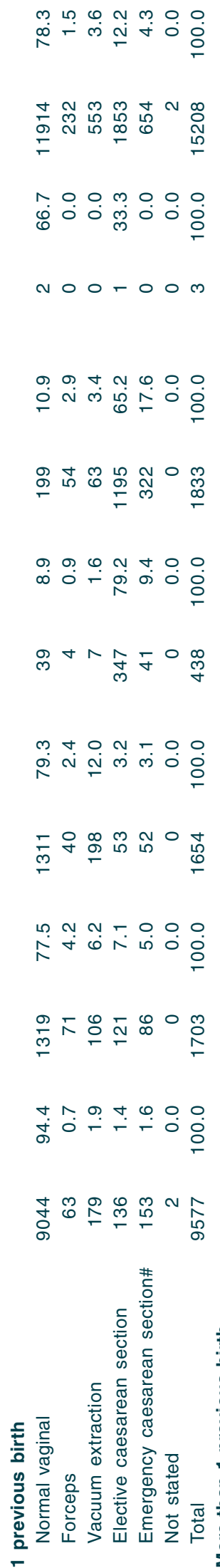 & 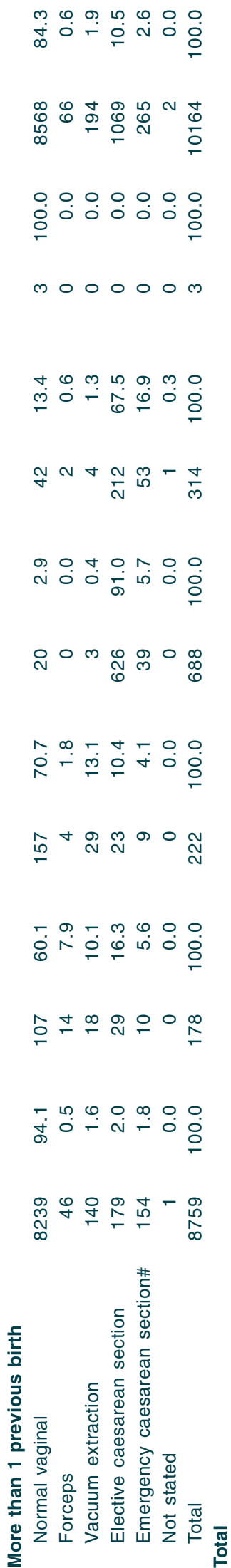 & 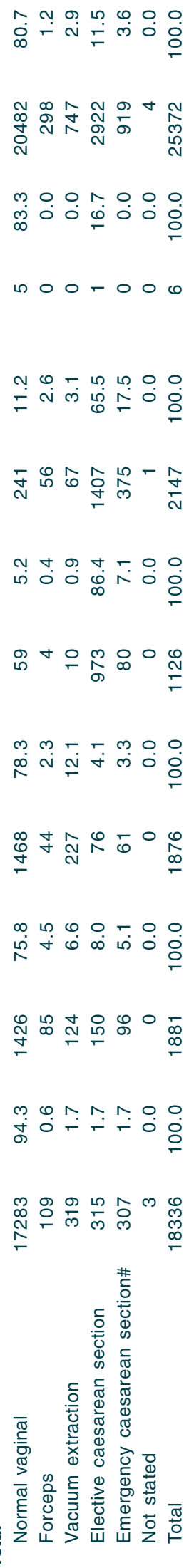 & 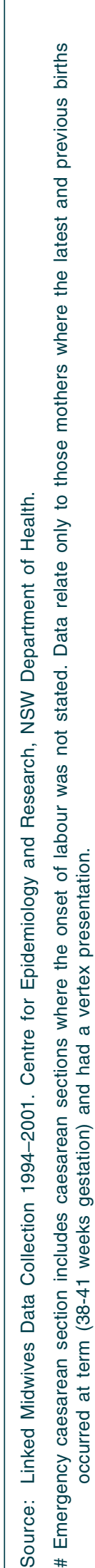 \\
\hline
\end{tabular}


Aboriginal or Torres Strait Islander mothers have remained over 10 per cent, one-and-a-half to two times higher than for NSW overall.

The report is the sixth annual report on mothers and babies in NSW and includes an additional chapter on repeat obstetric interventions among multiparous women giving birth in 2001. For women where both the latest and previous pregnancies were singleton with a vertex presentation and delivered at term, episiotomy, epidural anaesthetic, instrumental, and caesarean section delivery were all more likely to occur in the latest birth if they had occurred in the previous birth (Table 1) The highest rates for repeat intervention were seen for caesarean section delivery, with the rate of caesarean section being 93.5 per cent following previous elective caesarean section and 83.0 per cent following previous emergency caesarean section.

The report consolidates findings of the NSW Midwives Data Collection (MDC), the NSW Birth Defects Register, and the Neonatal Intensive Care Units Data Collection. It also contains summary information on maternal deaths and perinatal deaths in NSW, reviewed by the NSW Maternal and Perinatal Committee. The most common cause of perinatal death during 2002 was found to be unexplained death prior to birth, accounting for 26.3 per cent of all perinatal deaths (Figure 1). While down from 31.0 per cent in 2001 , the continuing high proportion of unexplained perinatal deaths highlights the importance of hospital or area-based reviews to assist in identifying potentially preventable factors.

The report New South Wales Mothers and Babies 2002 is available on the NSW Department of Health's website at www.health.nsw.gov.au/publichealth/mdc/mdcrep02.html. 